\title{
Clinical Study \\ Clinical Significance of Auditive Involvement in Rheumatoid Arthritis: A Case-Control Study
}

\author{
Laura Alonso, ${ }^{1}$ Ileana Gutierrez-Farfan, ${ }^{1}$ Angelica Peña-Ayala, ${ }^{1}$ \\ Maria-Esther Perez-Bastidas, ${ }^{2}$ and Rolando Espinosa ${ }^{3}$ \\ ${ }^{1}$ Audiology Department, Instituto Nacional de Rehabilitación, Avenida México-Xochimilco 289, Arenal de Guadalupe, Tlalpan, \\ 14389 México City, Mexico \\ ${ }^{2}$ Centro de Estudios de Investigación Básica y Clínica, Justo Sierra 2821-4 Vallarta Norte, 44690 Guadalajara, Mexico \\ ${ }^{3}$ Rheumatology Department, Instituto Nacional de Rehabilitación, Avenida México-Xochimilco No. 289, Torre de Ortopedia, \\ 2do Piso. Arenal de Guadalupe, Tlalpan, 14389 México City, Mexico
}

Correspondence should be addressed to Rolando Espinosa, rolespi@yahoo.com

Received 15 December 2010; Accepted 6 January 2011

Academic Editors: J. N. Ablin and P. Picco

Copyright (C) 2011 Laura Alonso et al. This is an open access article distributed under the Creative Commons Attribution License, which permits unrestricted use, distribution, and reproduction in any medium, provided the original work is properly cited.

Introduction. Rheumatoid arthritis (RA) can involve the incudomalleolar or incudostapedial articulations. Objective. To know the punctual prevalence of audiological alterations in patients with RA. Patients and Methods. RA patients and their controls (Cs), were evaluated by Tonal Audiometry (AU); if there were alterations in the air conduction (AC), bone conduction (BC), Logoaudiometry (LG), and Tympanometry (T) were performed. Results. 45 RA patients and 45 Cs were evaluated. RA patients had $40 \%$ of bilateral and $17.8 \%$ unilateral alteration versus Cs with $22.2 \%$ bilateral and $4.4 \%$ unilateral alteration versus Cs with $22.2 \%$ bilateral and 4.4\% unilateral in AC audiometry. In conventional T (CT) As-type curves in patients with RA, there were $22 \mathrm{LE}(48.8 \%)$ and 26 $\mathrm{RE}(57.7 \%)$ versus Cs, there were16 RE (35.5\%) and $20 \mathrm{LE}(44.4 \%)$. In High-frequency T (HFT): the 3B1G pattern in RA more frequent versus Controls $(\mathrm{Cs})$ in $\mathrm{RE}(P=.002$ and $\mathrm{LE}(P=.01)$. There were no differences according to RA activity or RA disease evolution. Conclusions. There is a greater tendency of auditive loss of As curves in CT (rigidity in ossicular chain) and of the 3B1G pattern in HFT in RA.

\section{Introduction}

Rheumatoid arthritis (RA) is a systemic disease characterized by inflammation of the synovial tissue with anatomical and functional repercussion in the articulations $[1,2]$. The incudomalleolar and incudostapedial articulations are small diarthrodial articulations $[3,4]$; involvement of these articulations has been reported in patients with RA [5-9]. Audiometric findings reported in these patients are conductiveand sensory-type hypoacousias $[8,9]$. Conductive-type hypoacousia-associated factors comprise laxitude of the ear's transductor mechanisms [3] and rigidity of the middle ear [9]; for neurosensory-type hypoacousia, immunological alterations have been proposed, such as the presence of specific antigens at the inner ear level, autoimmune complexrelated neurovascular damage, and lymphocyte B- and Tmediated autoimmunity $[6,10]$ and the use of ototoxic drugs such as methotrexate, hydroxychloroquine, and nonsteroidal anti-inflammatory drugs (NSAIDS) [11-16].

RA is a pathology that causes musculoskeletal disability and probably auditive involvement. The aim of this study was to establish the prevalence and type of auditive involvement in patients with RA, and to correlate this auditive disfunction with disease activity and duration.

\section{Materials and Methods}

We carried out a descriptive and observational study of paired cases and controls in a cohort. Cases were consecutive patients at the out-patient consulting office of the Rheumatology Department who fulfilled the following inclusion criteria: classification of RA according to the American College of Rheumatology (ACR) [17], both genders, aging 20 to 65 years, and with voluntary acceptance to participate 
in the study. The control group was made up of healthy persons who accompanied the patients seen at the institute; these individuals were age- and gender-paired with the cases. Exclusion criteria for both groups comprised patients with a history of infectious vascular middle ear and/or inner ear pathology during the last 12 months, prior middle ear surgery, exposure to occupational-type acoustic trauma, head and neck neoplasias, cranial trauma, inner ear pathology, antecedent of ototoxic drug use-related hypoacousia, and RA-dissimilar systemic autoimmune disease dissimilar in the group of cases. All participants signed a letter of informed consent.

2.1. Variables Evaluated. We collected demographic data on patients by means of a predesigned questionnaire and evaluated RA activity with the Disease Activity Score (DAS) 28 [18], classifying activity as follows: inactive $<2.6$; slight $>2.6$ and $<3.2$; moderate 3.2 and $<5.1$, severe $>5.1$. RA disease evolution was categorized in years, and we carried out the following audiological studies:

(i) tonal audiometry with AC 40 audiometry-type equipment from Interacoustics,

(a) by air conduction test, to obtain the auditive threshold, considering auditive loss with a threshold $>20 \mathrm{~dB}$ in one or more frequencies $[19,20]$,

(b) bone conduction test, performed in patients with some alteration in the air conduction test, for later auditive loss classification in conductive (air-bone gap $>15 \mathrm{~dB}$ ), sensory (gap $<15 \mathrm{~dB}$ ), or mixed conductive as well as sensory frequencies [21],

(ii) logoaudiometry (LG), obtaining the word detectability threshold, intelligibility threshold, and maximum comprehension by means of the average threshold in speech frequencies $(500 \mathrm{~Hz}$ and 1 and $2 \mathrm{KHz}$ ) [21],

(iii) impedanciometry: to evaluate middle ear function with the Ampliad brand model 775 (regulated by ANSI 3.39) impedanciometry,

(a) 226-Hz tympanometry, classifying the results according to Jerger based on compliance and pressure in the following curves: type A (normal compliance and pressure), type As (diminished compliance and normal pressure), type Ad (increased compliance and normal pressure), type B (flat tympanogram), and type C (displaced to negative pressures) [22].

(b) high-frequency tympanometry, classifying results according to the model of Vanhuyse in patterns $1 \mathrm{~B} 1 \mathrm{G}$ and $3 \mathrm{~B} 1 \mathrm{G}$ (characteristics of rigidity) and of $3 \mathrm{~B} 3 \mathrm{G}$ and $5 \mathrm{~B} 3 \mathrm{G}$ (characteristics of mass) [22].
2.2. Analysis of the Results. We conducted a descriptive analysis of the demographic variables utilizing parametric statistics: student $t$ test for comparison of means, and $\chi^{2}$ test for comparison of proportions. We carried out a subanalysis, dividing the group into individuals $>35$ and $<35$ years of age [23] to avoid degenerative hypoacousia-related classification bias and employing nonparametric statistics with the MannWhitney $U$ test for comparing differences of means and the Fisher exact test for comparing categorical variables.

\section{Results}

We screened 53 patients with a diagnosis of RA: eight of these patients were excluded due to Meniere's syndrome, eustachian tube dysfunction, and being aged $>65$ years. A total of 45 patients with RA were studied; these patients were paired with 45 healthy subjects, who made up the control group. In total, we studied 90 ears in each study group. In Table 1, we observe the demographic characteristics of the studied patients. A total of $91 \%$ of patients were of feminine gender, with an average age of 44.1 years. High blood pressure was the most frequently encountered comorbidity; $78 \%$ of patients with RA had $>2$ years of disease evolution. The most commonly employed drug in patients with RA was methotrexate in combination with a second drug; $24 \%$ took steroids and $73 \%$ nonsteroidal anti-inflammatory drugs (NSAIDS).

3.1. Tonal Audiometry: Air Conduction Test. In the group of patients with RA, we found 19 subjects (42.2\%) with normal air conduction, 18 patients $(40 \%)$ with bilateral alteration, and eight patients with unilateral alteration versus the control group, in which we detected 33 subjects (73.3\%) without alterations, 10 subjects $(22.2 \%)$ with bilateral alteration, and only two $(4.4 \%)$ with unilateral alteration $(P=.008)$ (Figure 1). Patients with audiometric involvement in the RA group were younger (mean age: 48.7 years) than the healthy subjects (mean age: 55.3 years), with this being statistically significant $(P=.02)$ (Table 2$)$. On performing a subanalysis by affected ear, we found no differences in the proportion of involvement between the right ear (RE) and left ear (LE) (Table 2).

3.2. Mean Threshold by Frequency. Patients with RA tend to have deterioration in high- and low-frequency auditive thresholds compared with the controls, with this being statistically significant at frequencies of $0.125,0.250$, and $8 \mathrm{KHz}$ $(P<.01)$, without observing differences in intermediate frequencies $(0.5,1$, and $2 \mathrm{KHz}$ ) (Figure 2).

3.3. Categorization by Age. On categorizing results by age, in individuals aging $<35$ years, patients with RA had greater deterioration in low-frequency auditive thresholds in comparison with controls, reaching statistical significance in RE at the frequency of $0.125(P=.01)$ and in LE at frequencies of $0.250(P=.03)$ and $0.500 \mathrm{KHz}(P=.04)$; we observed no differences in the remainder of frequencies. In the group of patients with RA aging $>35$ years, there was a tendency 
TABle 1: Demographic characteristics of the populations under study.

\begin{tabular}{|c|c|c|}
\hline Characteristic & Cases & Controls \\
\hline$N$ & 45 & 45 \\
\hline $\begin{array}{l}\text { Gender } \\
\text { (feminine) }\end{array}$ & $41(91.1 \%)$ & $41(91.1 \%)$ \\
\hline $\begin{array}{l}\text { Age (years) } \\
(\text { mean } \pm \mathrm{SD})^{*}\end{array}$ & $44.1(11.9)$ & $44.4(12)$ \\
\hline \multirow{3}{*}{ Comorbilidity $(n)$} & Dyslipidemia (1) & Dyslipidemia (1) \\
\hline & $\begin{array}{l}\text { Systemic high blood } \\
\text { pressure (4) }\end{array}$ & $\begin{array}{l}\text { Systemic high } \\
\text { blood pressure (2) }\end{array}$ \\
\hline & Diabetes mellitus (2) & \\
\hline \multicolumn{3}{|l|}{$\begin{array}{l}\text { Categorization by age } \\
\text { (years), } n(\%)\end{array}$} \\
\hline$<35$ & $12(27)$ & $13(28.9)$ \\
\hline$>35$ & $33(73)$ & $32(71.1)$ \\
\hline \multicolumn{3}{|l|}{ DAS $28, n(\%)$} \\
\hline Inactive & $8(18)$ & \\
\hline Slight activity & $9(20)$ & \\
\hline Moderate activity & $19(42)$ & \\
\hline Severe activity & $9(20)$ & \\
\hline \multicolumn{3}{|l|}{$\begin{array}{l}\text { RA evolution (years), } \\
n(\%)\end{array}$} \\
\hline$<2$ & $10(22)$ & \\
\hline $2-5$ & $14(31)$ & \\
\hline $5-10$ & $10(22)$ & \\
\hline$>10$ & $11(25)$ & \\
\hline \multicolumn{3}{|l|}{ Drugs utilized, $n(\%)$} \\
\hline Methotrexate & $35(78)$ & \\
\hline $\begin{array}{l}\text { Hydroxychloroquine/ } \\
\text { chloroquine }\end{array}$ & $24(53)$ & \\
\hline Anti-TNF & $7(15)$ & \\
\hline Leflunomide & $6(13)$ & \\
\hline Sulfasalazine & $6(13)$ & \\
\hline Rituximab & $5(11)$ & \\
\hline Steroids & $11(24)$ & \\
\hline NSAID & $33(73)$ & \\
\hline
\end{tabular}

* Age difference between groups $(P=0.27)$. SD: standard deviation; Disease Activity Score: DAS 28; Antitumoral necrosis Factor: Anti-TNF; NSAID: nonsteroidal anti-inflammatory.

toward having auditive thresholds $>8 \mathrm{KHz}$, without this reaching statistical significance (Figure 3 ).

3.4. Auditive Involvement and RA Activity. In inactive patients according to the DAS 28, we found elevation in mean auditive thresholds in LE; in an analysis of only patients $>35$ years of age, these differences were maintained. We found no difference in RE.

3.5. Categorization by Mean Disease Duration. No statistical significant differences were observed when air conduction test alterations were correlated with mean disease duration.

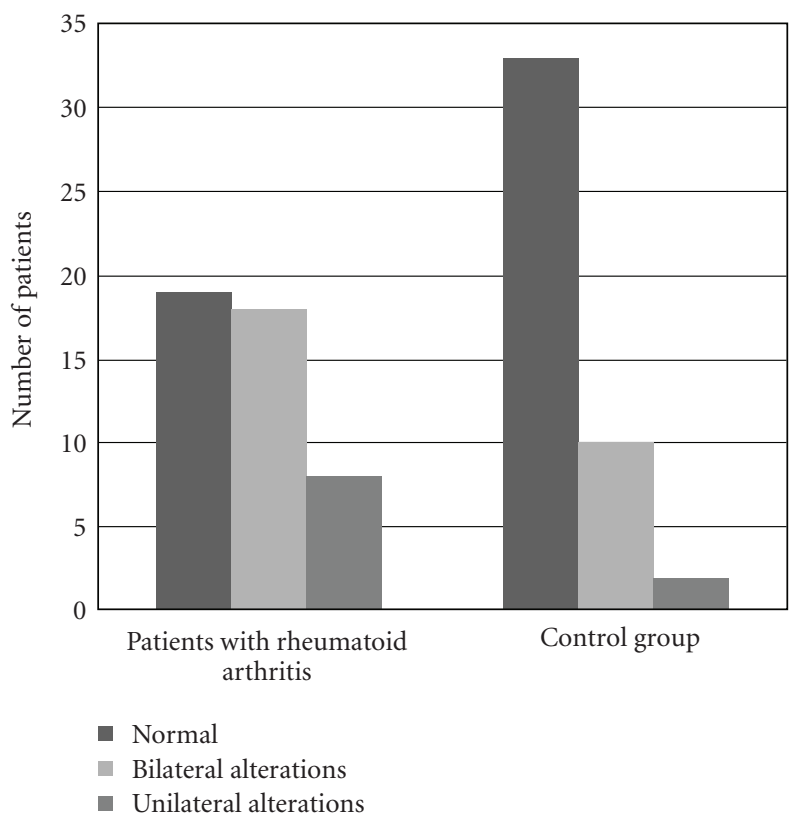

Figure 1: Air conduction test in study groups. Prevalence of hypoacusia was higher in RA patients compared with controls $(P=$ $.008)$.

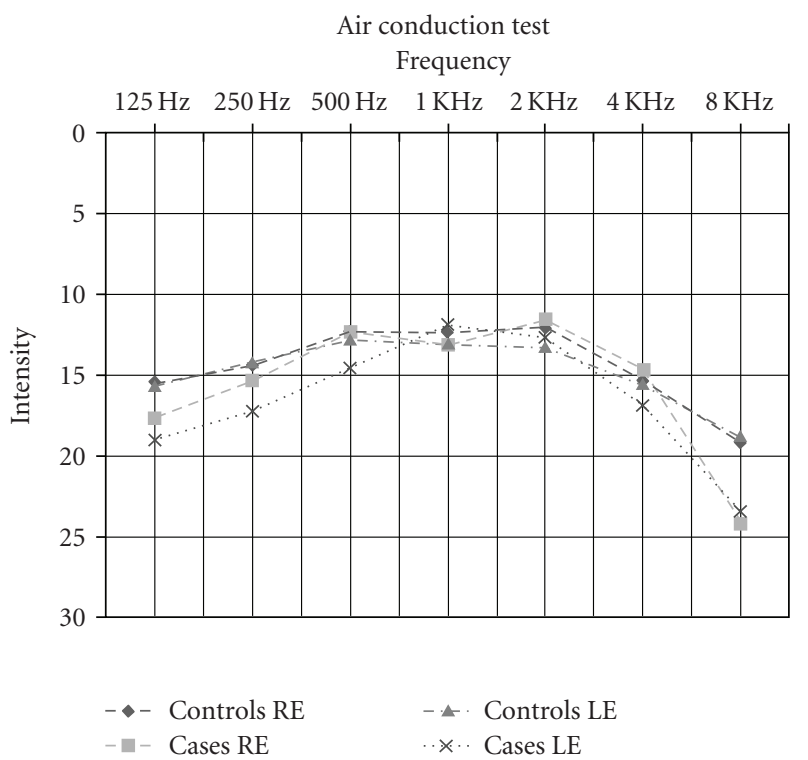

Figure 2: Mean audition threshold obtained by frequency in both study groups. The mean threshold in frequencies of $0.125,0.250$ and $8 \mathrm{KHz}$ showed higher decrease in RA patients versus control group. $(P<.01)$.

3.6. Tonal Audiometry: Bone Conduction Test. The proportion of sensory hypoacousia was that which was most frequently found in both groups, with the proportion of patients with RA at $45.5 \%$ versus $24.4 \%$ in the control group; conductive- or mixed-type hypoacousia was only found in some patients of the group with RA (Table 2). 
TABLE 2: Audiological results.

\begin{tabular}{|c|c|c|c|c|c|}
\hline & & & $\begin{array}{c}\text { Cases } 45 \\
n(\%)\end{array}$ & $\begin{array}{c}\text { Controls } 45 \\
n(\%)\end{array}$ & $P$ value \\
\hline \multicolumn{3}{|l|}{$\begin{array}{l}\text { Age (years) of } \\
\text { patients with } \\
\text { hypoacousia } \\
\text { Mean } \pm \text { SD }\end{array}$} & $48.7 \pm 10.6$ & $55.3 \pm 8.3$ & .02 \\
\hline \multirow{3}{*}{ Audiometry } & \multicolumn{2}{|c|}{ Normal } & $19(42.2)$ & $33(73.3)$ & \\
\hline & \multicolumn{2}{|c|}{ Bilateral alteration } & $18(40)$ & $10(22.2)$ & .008 \\
\hline & \multicolumn{2}{|c|}{ Unilateral alteration } & $8(17.8)$ & $2(4.4)$ & \\
\hline \multirow{2}{*}{$\begin{array}{l}\text { Audiometric } \\
\text { alteration }\end{array}$} & \multicolumn{2}{|c|}{ Right ear } & $21(46.7)$ & $12(26.6)$ & .049 \\
\hline & \multicolumn{2}{|c|}{ Left ear } & $23(51.1)$ & $10(22.2)$ & .004 \\
\hline \multirow{6}{*}{ Bone conduction } & \multirow{2}{*}{ Sensory hypoacousia } & Right ear & $19(42.2)$ & $12(26.6)$ & $>.05$ \\
\hline & & Left ear & $22(48.8)$ & $10(22.2)$ & $>.05$ \\
\hline & \multirow{2}{*}{ Conductive hypoacousia } & Right ear & $1(2.2)$ & 0 & $>.05$ \\
\hline & & Left ear & $1(2.2)$ & 0 & $>.05$ \\
\hline & \multirow{2}{*}{ Mixed hypoacousia } & Right ear & $1(2.2)$ & 0 & $>.05$ \\
\hline & & Left ear & 0 & 0 & $>.05$ \\
\hline Logoaudiometry & & & $2(4.4)$ & 0 & $>.05$ \\
\hline \multirow{4}{*}{$\begin{array}{l}\text { Tympanometry } \\
226 \mathrm{~Hz}\end{array}$} & \multirow{2}{*}{ Right ear } & Curve A & $23(51.1)$ & $29(64.4)$ & \multirow{2}{*}{.2} \\
\hline & & Curve As & $22(48.8)$ & $16(35.5)$ & \\
\hline & \multirow{2}{*}{ Left ear } & Curve A & $19(42.2)$ & $25(55.5)$ & \multirow{2}{*}{.2} \\
\hline & & Curve As & $26(57.7)$ & $20(44.4)$ & \\
\hline \multirow{4}{*}{$\begin{array}{l}\text { High-frequency } \\
\text { tympanometry }\end{array}$} & \multirow{2}{*}{ Right ear } & $1 \mathrm{~B} 1 \mathrm{G}$ & $32(71.1)$ & $43(95.5)$ & \multirow{2}{*}{.002} \\
\hline & & $3 \mathrm{~B} 1 \mathrm{G}$ & $13(28.8)$ & $2(4.4)$ & \\
\hline & \multirow{2}{*}{ Left ear } & $1 \mathrm{~B} 1 \mathrm{G}$ & $33(73.3)$ & $42(93.3)$ & \multirow{2}{*}{.01} \\
\hline & & $3 \mathrm{~B} 1 \mathrm{G}$ & $12(26.6)$ & $3(6.6)$ & \\
\hline
\end{tabular}

3.7. Logoaudiometry. Only two patients (4.4\%) of the group with RA had maximum phonemic discrimination threshold displacement.

3.8. 226-HZ Tympanometry. A total of $53.2 \%$ of patients with RA had As-type curve (rigidity of the tympanoossicular complex) compared with control subjects (39.9\%); although we observed a tendency for ossicular-chain rigidity, we found no statistically significant difference $(P=.2)$ (Table 2).

3.9. High-Frequency Tympanometry. In both groups, the most frequently encountered pattern was $1 \mathrm{~B} 1 \mathrm{G}$, although the group of patients with RA presented the $3 \mathrm{~B} 1 \mathrm{G}$ pattern with greater frequency $(27.7 \%)$ compared with the control group $(5.5 \%)(P=.002$ in RE and $P=.011$ in LE, Table 2).

\section{Discussion}

The objective of the study was to compare the prevalence of auditive alterations in patients with RA versus a control group. In our study, we found that patients with RA had a greater prevalence of hypoacousia compared with healthy subjects, this is similar to that reported previously by Takatsu et al., Raut et al., and García Callejo et al. [4, 9, 24]; however, in a study published recently by Halligan, the authors observed no difference in the proportion of patients with RA and healthy subjects who had hypoacousia and types of auditive loss. One difference with our study is the age range of the patients studied: the patients in the Halligan et al. study ranged in age from 40 to 69 years; thus, the control group could have had a selection bias on having patients with degenerative-type hypoacousia. The study did not conduct age categorization in order to diminish this type of bias [5].

The prevalence of neurosensory hypoacousia was the most frequent in our patients, this is similar to that reported by Takatsu et al., Halligan et al., and Raut et al. Probably, the cause of greater neurosensory hypoacousia can be due to autoimmune-type etiologies, as well as to the use of ototoxic drugs. The prevalence of conductive- or mixedtype hypoacousia has been reported less frequently. In our study, we found no healthy subject with these hypoacousia types, probably because our inclusion and exclusion criteria were strict; this is different from other studies $[4,5,9]$, in which inclusion criteria were less strict, and this can result in inappropriate selection of control subjects. For example, the results of the study carried out by Salvinelli et al. reported mixed hypoacousia as the most frequent type, differing from our study [6].

On analyzing thresholds obtained by frequency, we observed that patients with RA tend to present auditive 


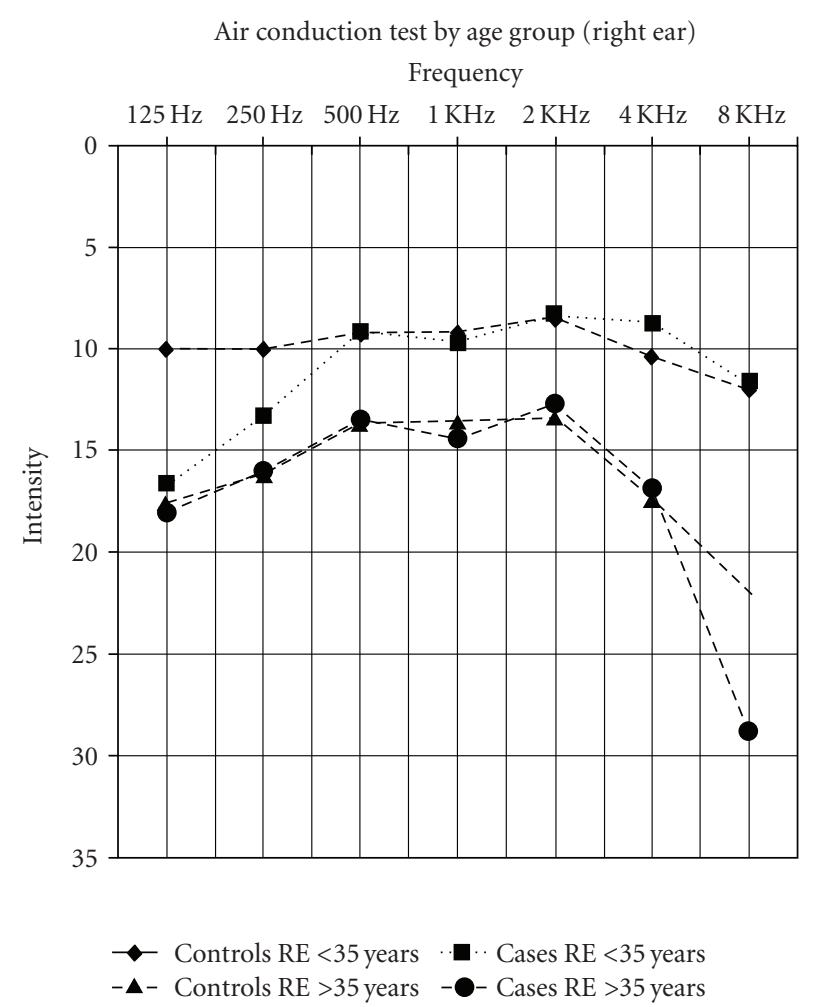

(a)

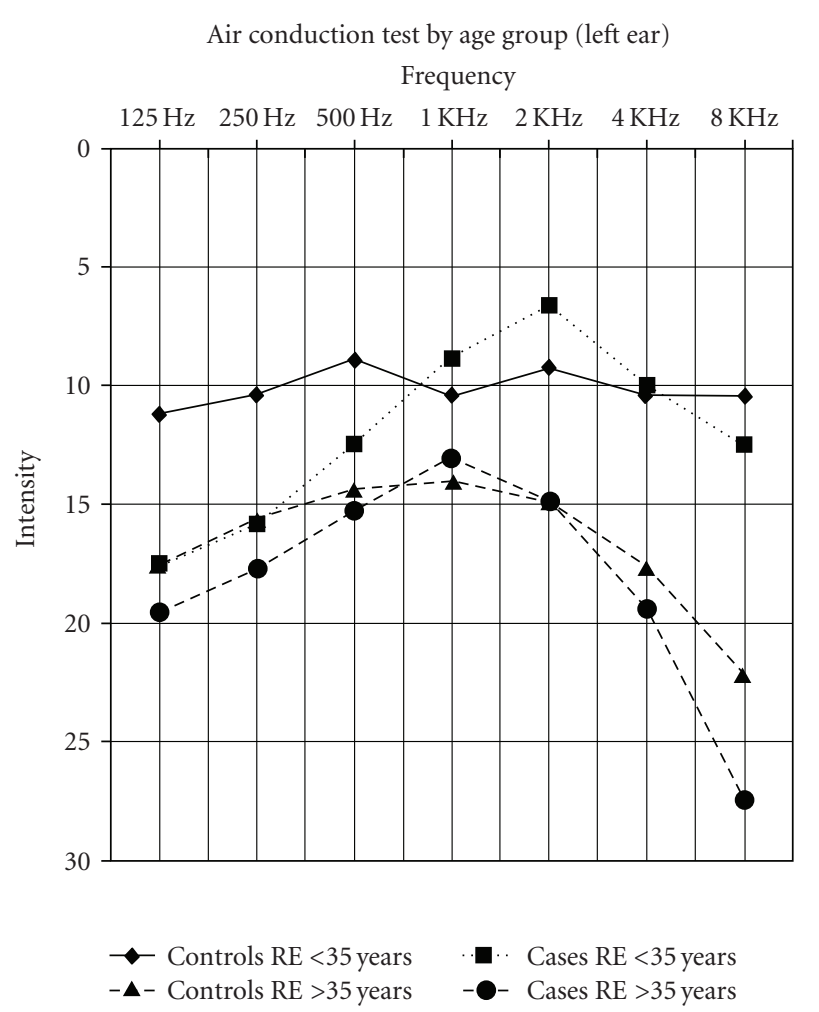

(b)

Figure 3: Mean hearing levels obtained by frequency by age group of both groups of subjects. In RA patients younger 35 years old in frequencies $0.125 \mathrm{KHz}(P=.01)$ in right ear; $0.25 \mathrm{KHz}(P=.03)$ and $0.500 \mathrm{KHz}(P=.04)$ in left ear, showed higher decreased in mean auditive threshold.

threshold deterioration; frequencies of 0.125 and $0.250 \mathrm{KHz}$ are those that consistently have been affected in our study as well as in previous reports $[4,6,9,10,25]$.

With the exception of the study conducted by Murdin et al. in which the study subjects were $<50$ years of age [10], the remainder of the studies have been performed in patients with RA aging $>50$ years, in whom there is an age-related degenerative factor. It is known that after the age of 65 years, the prevalence of degenerative hypoacousia ranges from 20 to $40 \%[26,27]$; thus, we categorized our study groups as $<35$ and $>35$ years of age, finding that patients with RA aging $<35$ years had auditive thresholds at greater intensities in low frequencies as compared with controls, this is statistically significant at frequencies of $0.125,0.250$, and $0.500 \mathrm{KHz}$. We observed no differences in the remainder of frequencies; we can associate this with a nearly imperceptible defect of air transmission at the ossicular-chain level. This finding does not persist in patients $>35$ years of age, which is probably due to that there are degenerative-type factors that begin to affect patients with RA as well as healthy subjects. Therefore, the difference is no longer evident of low frequencies, as we observe in Figure 3. Now and then, in the group of patients with RA $<35$ years of age, we observed a tendency toward greater deterioration in auditive threshold at $8 \mathrm{KHz}$, which can indicate that the autoimmune process and the use of ototoxic drugs can affect these frequencies without being able to isolate the degenerative process.

In earlier studies, attempts were made to relate hypoacousia and RA disease activity; reports only included greater auditive involvement in patients with active RA in comparison with patients with inactive RA in the study performed by Salvinelli et al. [6]. This was different from the study of Halligan et al. [5], who found no differences. In our study, we found no differences between disease activity and involvement at the ear level, although we observed tendencies; but on categorizing our sample of patients with RA, the subgroups were very small. We think that future studies should include a greater number of patients and should corroborate this finding, which is controversial.

In the LG, we only found displacement of maximum phonetic discrimination thresholds at greater intensities in two patients with RA and in no healthy subject, this is because speech frequencies $(500,1,000$, and $2,000 \mathrm{~Hz})$ were found to be generally conserved in our study group.

In conventional tympanometry $(226-\mathrm{Hz})$, we found that patients with RA presented A-type curves more frequently than the control group, this is compatible with greater rigidity at the ossicular-chain level, as reported by Salvinelli et al. [6] and Takatsu et al. [4]. In studies conducted by Takatsu et al. [4] and Raut et al. [9], it is noteworthy that 
the authors report type-Ad (increase in compliance) and C-type curves (pressure displaced to negativity) of Jerger, data that should not be present (mainly that of displacement to negative pressures) because this could be suggestive of middle ear pathology, as is the case of a tubal dysfunction that can affect the result in all audiometric studies. Halligan et al. [5] report the tympanometric study only as normal and abnormal, without specifying whether the abnormality loss is due to alterations in compliance and/or pressure, and they consider from 0.3 to $1.5 \mathrm{cc}$ as levels of normality in compliance, when in adults normality ranges comprise 0.5 to $1.5 \mathrm{cc}$.

In high-frequency tympanometry in both groups, we found patterns of normality ( 1 - and $3 \mathrm{~B} 1 \mathrm{G})$, both characteristic of rigidity. However, it is evident that the $3 \mathrm{~B} 1 \mathrm{G}$ pattern is more characteristic of patients with RA in comparison with subjects in the control group.

In our study, we did not carry out an otoacoustic emissions study, and the results in the previous studies are controversial. The group of Halligan et al. [5] did not report differences between patients with RA and healthy subjects, in contrast with the study conducted by Murdin et al. whose authors reported a high proportion of patients with RA who presented absence of reproducibility in transitory otoacoustic emissions; they consider this study to be a probable predictor of hypoacousia in asymptomatic patients [10].

The strengths of our study include the number of patients evaluated and the diminution of the degenerative factor on possessing a lower age range, as well as the subanalysis we performed between individuals $>35$ and $<35$ years of age and exclusion of middle ear and/or inner ear pathology. However, in future studies, a sample calculation should be made, taking into account the information available for finding an association of hypoacousia in patients with RA and conducting all of the systematic studies in the patients, such as bone conduction test, because we only performed this on finding auditive threshold deterioration, so as to be able to evaluate the air-bone gap in the study groups, in order to carry out prospective and longitudinal-type designs and to include patients with early-onset RA, as well as to be able to know the incidence of audiological involvement in patients with RA, to evaluate risk factors, and to control variables such as medical treatment and comorbidities.

\section{Conclusions}

In the present study, we found a prevalence of $>57 \%$ air conduction involvement in patients with RA, with sensorytype hypoacousia being the most frequently encountered; however, we also found conductive- and mixed-type hypoacousia. These two hypoacousia types were exclusive findings in patients with RA. Auditive thresholds in patients with RA exhibit deterioration in relation to the control group. In the 226-Hz tympanometry studies, there was diminished compliance with greater frequency in patients with RA, which can be translated into rigidity at the ossicular chain level. In high-frequency tympanometries, we found that the $3 \mathrm{~B} 1 \mathrm{G}$ was the most prevalent pattern in patients with RA.
We found no relationship between RA disease evolution time and disease activity with alteration in audiological studies.

\section{Acknowledgment}

The authors would like to thank Leticia Hernández-González for her assistance in coordinate schedule patients.

\section{References}

[1] P. E. Lipsky, "Rheumatoid arthirtis," in Harrison's Principles of Internal Medicine, E. Braunwald, A. Fauci, D. Kasper, S. Hauser, D. Longo, and L. Jameson, Eds., McGraw-Hill, New York, NY, USA, 15th edition, 2001.

[2] D. B. Hellmann and J. H. Stone, "Artritis y trastornos musculoesqueleticos," in Diagnóstico Clínico y Tratamiento, L. Tierney, S. McPhee, and M. Papadakis, Eds., Manual Moderno, 38th edition, 2003.

[3] C. Frade and C. Martin, "Diagnostic value of the multifrequency tympanometry in active rheumatoid arthritis," Auris Nasus Larynx, vol. 25, no. 2, pp. 131-136, 1998.

[4] M. Takatsu, M. Higaki, H. Kinoshita, Y. Mizushima, and I. Koizuka, "Ear involvement in patients with rheumatoid arthritis," Otology and Neurotology, vol. 26, no. 4, pp. 755-761, 2005.

[5] C. S. Halligan, C. D. Bauch, R. H. Brey et al., "Hearing loss in rheumatoid arthritis," Laryngoscope, vol. 116, no. 11, pp. 2044-2049, 2006.

[6] F. Salvinelli, F. Cancilleri, M. Casale et al., "Hearing thresholds in patients affected by rheumatoid arthritis," Clinical Otolaryngology and Allied Sciences, vol. 29, no. 1, pp. 75-79, 2004.

[7] V. Colletti, F. G. Fiorino, L. Bruni, and D. Biasi, "Middle ear mechanics in subjects with rheumatoid arthritis," Audiology, vol. 36, no. 3, pp. 136-146, 1997.

[8] M. Özcan, F. M. Karakuş, O. Gündüz, Ã. Tuncel, and H. Şahin, "Hearing loss and middle ear involvement in rheumatoid arthritis," Rheumatology International, vol. 22, no. 1, pp. 1619, 2002.

[9] V. V. Raut, J. Cullen, and G. Cathers, "Hearing loss in rheumatoid arthritis," Journal of Otolaryngology, vol. 30, no. 5, pp. 289-294, 2001.

[10] L. Murdin, S. Patel, J. Walmsley, and L. H. Yeoh, "Hearing difficulties are common in patients with rheumatoid arthritis," Clinical Rheumatology, vol. 27, no. 5, pp. 637-640, 2008.

[11] F. A. Boettcher and R. J. Salvi, "Salicylate ototoxicity: review and synthesis," American Journal of Otolaryngology, vol. 12, no. 1, pp. 33-47, 1991.

[12] J. T. Halla and J. G. Hardin, "Salicylate ototoxicity in patients with rheumatoid arthritis: a controlled study," Annals of the Rheumatic Diseases, vol. 47, no. 2, pp. 134-137, 1988.

[13] R. Bortoli and M. Santiago, "Chloroquine ototoxicity," Clinical Rheumatology, vol. 26, no. 11, pp. 1809-1810, 2007.

[14] H. Schuknecht, "Disorders of intoxication," in Pathology of the Ear, H. Schuknecht, Ed., Lea \& Febiger, Philadelphia, Pa, USA, 2nd edition, 1993.

[15] J. M. Sánchez-Fernández, A. Martínez-Ibargüen, F. Santaolalla-Montoya, A. Sánchez del rey, and A. Macías-Fernández, "Laberintotóxia," in El Sistema Vestibular y sus Alteraciones, J. Bartual and N. Pérez, Eds., Editorial Panamericana, Barcelona, Spain, 1st edition, 1999. 
[16] L. Gil-Carcedo, L. Vallejo, and E. Gil-Carcedo, "Ototoxicidad," in Otología, L. Gil-Carcedo, L. Vallejo, and E. Gil-Carcedo, Eds., Editorial Panamericana, Barcelona, Spain, 2nd edition, 2004.

[17] G. S. Alarcón, W. D. Blackburn, A. Calvo, and O. Castañeda, "Evaluation of the American Rheumatism Association preliminary criteria for remission in rheumatoid arthritis: a prospective study," Journal of Rheumatology, vol. 14, no. 1, pp. 93-96, 1987.

[18] DAS-Score. NL. Available at: Van Riel, Piet L.C.M., "DAS Score.NL," University Medical Centre Nijmegen-The Netherlands, September 2010, http://www.das-score.nl.

[19] A. Parving and B. Christensen, "On criteria for hearing impairment in children," International Journal of Pediatric Otorhinolaryngology, vol. 24, no. 1, pp. 1-9, 1992.

[20] R. M. Irving and R. J. Ruben, "The acquired hearing losses of childhood," in Pediatric Otology and Neurotology, A. Lalwani and K. Grundfast, Eds., Lippincot-Raven, Philadelphia, Pa, USA, 1998.

[21] P. A. Yantis, "Pure air conduction threshold testing. Donald D. Dirks. Bone-conduction threshold testing. John P. Pendrod. Speech threshold and word recognition/discrimination testing," in Handbook of Cinical Audiology, J. Katz, R. Burkard, and L. Medwetsky, Eds., Lippincott Williams \& Wilkins, Philadelphia, Pa, USA, 4th edition, 2002.

[22] D. Osguthorpei and W. Melnick, "Principios básicos y aplicaciones de la timpanometría," Otolaryngologic Clinics of North America, vol. 2, pp. 295-325, 1991.

[23] R. Hinojosa and R. F. Naunton, "Presbiacusia," in Otorrinolaringología: Otología y Neurootología, M. Paparella, D. Shumrick, J. Gluckman, and W. Meyerhoff, Eds., Editorial Panamericana, Buenos Aires, Argentina, 3rd edition, 1994.

[24] F. J. García Callejo, N. C. Tobías, N. M. Fernández, C. de Paula Vernetta, I. A. Castañeira, and J. M. Algarra, "Hearing impairment in patients with rheumatoid arthritis," Acta Otorrinolaringologica Espanola, vol. 58, no. 6, pp. 232-238, 2007.

[25] A. O. Ikiz, E. Unsal, G. Kirkim, T. K. Erdag, and E. A. Guneri, "Hearing loss and middle ear involvement in patients with juvenile idiopathic arthritis," International Journal of Pediatric Otorhinolaryngology, vol. 71, no. 7, pp. 1079-1085, 2007.

[26] J. Jerger, R. Chmiel, N. Wilson, and R. Luchi, "Hearing impairment in older adults: new concepts," Journal of the American Geriatrics Society, vol. 43, no. 8, pp. 928-935, 1995.

[27] M. Bance, "Hearing and aging," Canadian Medical Association Journal, vol. 176, no. 7, pp. 925-927, 2007. 


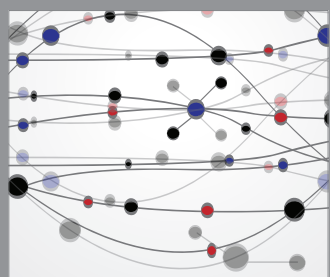

The Scientific World Journal
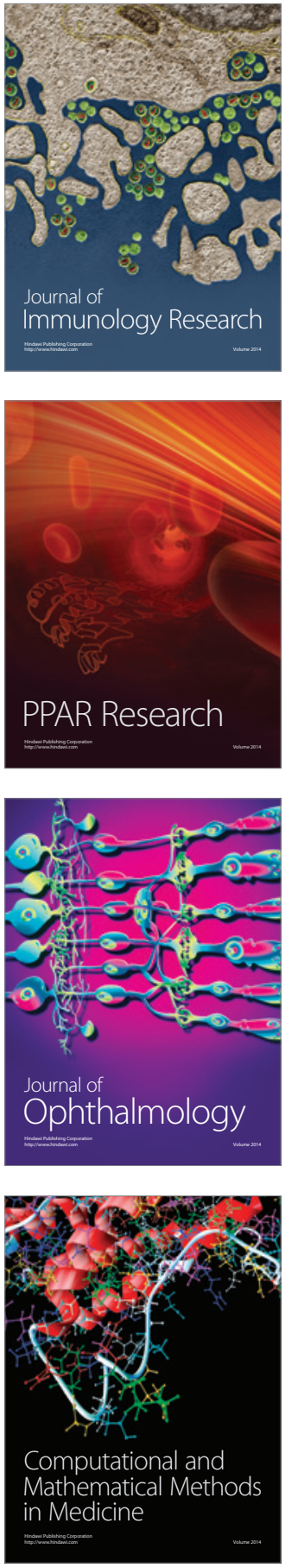

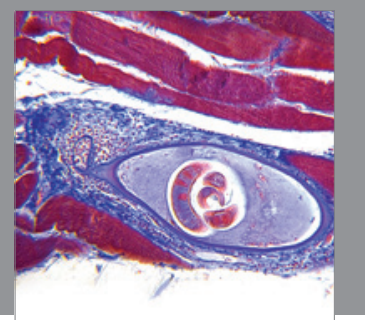

Gastroenterology

Research and Practice
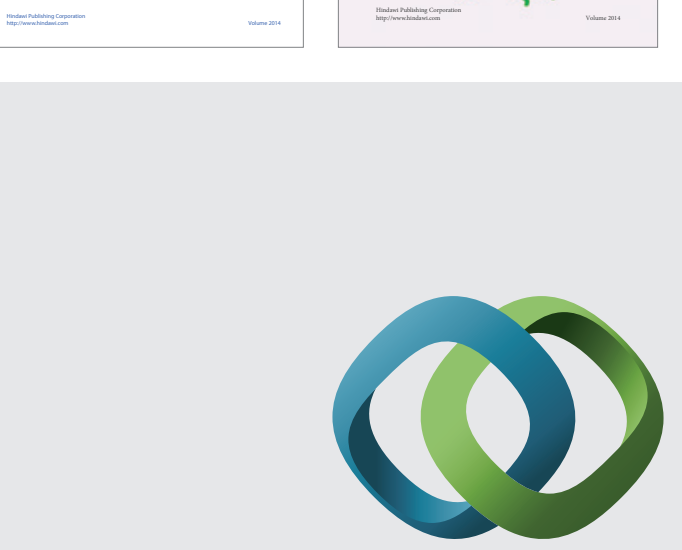

\section{Hindawi}

Submit your manuscripts at

http://www.hindawi.com
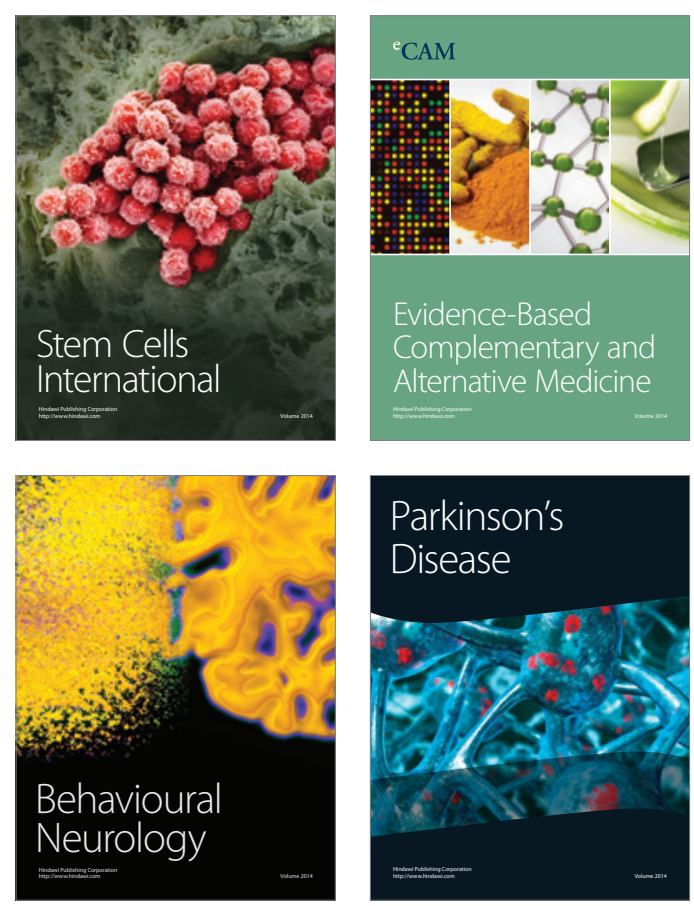

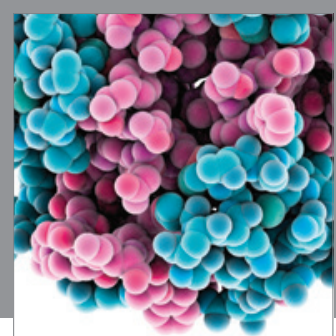

Journal of
Diabetes Research

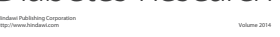

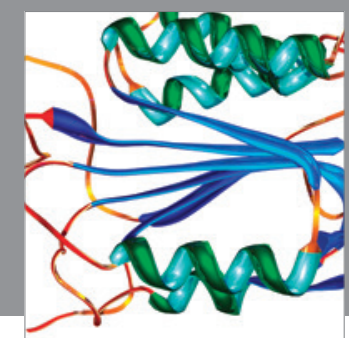

Disease Markers
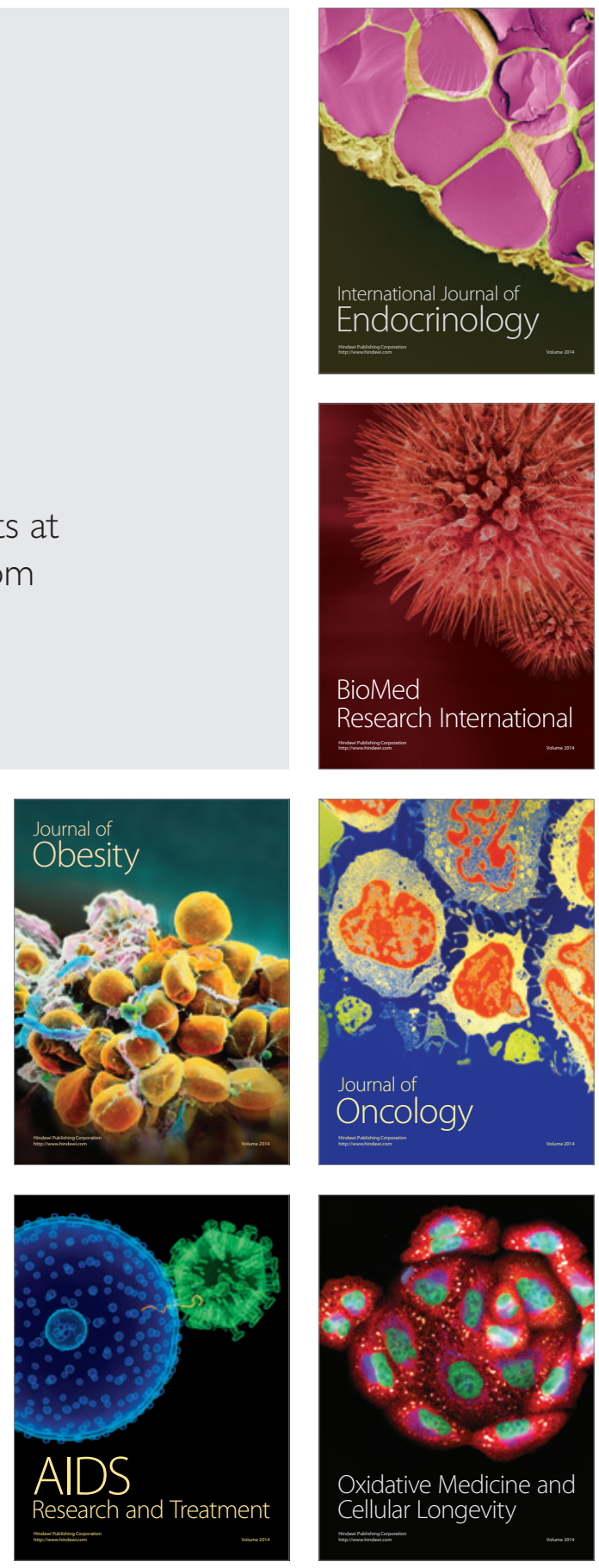